\title{
COMPLICAÇÕES ORAIS ASSOCIADAS AOS TRANSPLANTADOS DE ÓRGÃOS E TECIDOS: REVISÃO DE LITERATURA
}

\author{
Oral complications associated to organ and tissue transplants: a literature review
}

\author{
Paulo Sergio da Silva Santos', Fabrício Bitu², Fabio Luiz Coracin ${ }^{3}$, Romano Mancusi Sobrinho ${ }^{4}$, Roberto Brasil Lima
}

\begin{abstract}
RESUMO
Alterações bucais podem ser importantes para a investigação de comprometimentos sistêmicos, principalmente quando relacionados à condição de imunossupressão em transplantes, e há o risco de infecções. No crescente aumento do número de pacientes transplantados de órgãos e tecidos, tem-se tornado fundamental a formação de equipes multidisciplinares para atender pacientes transplantados, das quais a Odontologia pode e deve ser parte. Esta revisão de literatura propõe-se a apresentar e discutir a relevância das complicações bucais relacionadas às condições antes e após transplantes de órgãos e tecidos, as quais podem gerar complicações graves e, conseqüentemente, interferir no sucesso da terapêutica médica.
\end{abstract}

Descritores: Manifestações bucais, Odontologia, Transplantes, Transplante de medula óssea, Infecções bacterianas, Infecções virais, Infecções fúngicas.

\footnotetext{
Instituições:

1 Cirurgião Dentista da Santa Casa de Misericórdia de São Paulo e do Centro de Atendimento a Pacientes Especiais (CAPE/FOUSP) - São Paulo / SP

2 Núcleo de Estudos em Pacientes Especiais (NEPE) da Universidade Federal do Ceara Fortaleza / CE

3 Serviço de Transplante de Medula Óssea do Hospital das Clínicas (FMUSP) - São Paulo / SP

${ }^{4}$ Serviço de Medicina Bucal do Hospital Alemão Osvaldo Cruz - São Paulo / SP

5 Serviço de Odontologia do Hospital Geral de Guarulhos - São Paulo / SP
}

\section{Correspondência:}

Paulo Sérgio da Silva Santos

Rua Aureliano Coutinho, 278 - Cj. 21 - São Paulo / SP - CEP: 01224-020 - Brasil

Tel.: (11) 36669683

E-mail: paulosergiosilvasantos@gmail.com

Recebido em: 11.02.2009

Aceito em: 23.03.2009

\section{INTRODUÇÃO}

Infecções bucais são ameaças que podem causar infecções sistêmicas e provocar rejeição do órgão transplantado. Dentre as fontes de infecção bucal que podem gerar algum comprometimento nesse grupo de pacientes, as mais comuns são: cárie dental, doenças pulpares, doenças periodontais, infecções oportunistas (fúngicas e virais) e outras complicações decorrentes de procedimentos odontológicos. Este artigo tem o objetivo de trazer informações úteis para toda equipe multiprofissional em transplantes de órgãos e tecidos sobre doenças bucais e os cuidados odontológicos relevantes para o atendimento desses pacientes.

\section{INFECÇÕES ORAIS PRÉ E PÓS-TRANSPLANTE Cárie Dentária}

A cárie dentária é uma doença transmissível resultante da difusão de ácidos decorrentes do metabolismo de carboidratos produzidos por bactérias presentes no biofilme bucal, que causam a dissolução do componente mineral do dente. ${ }^{1}$ É um processo contínuo derivado de vários ciclos de desmineralização e remineralização, onde a desmineralização se inicia na superfície dos cristais do esmalte e/ou dentina e culmina com a formação de uma cavidade na estrutura dentária. ${ }^{1}$

Dentre as diversas causas de infecções pós-transplante, as de origem dentária raramente são citadas., ${ }^{2,3}$ Vários estudos fazem referência à condição de saúde bucal e ao índice de cáries dentárias pós-transplantes, seja de órgãos sólidos ${ }^{4-6}$ ou de medula óssea. ${ }^{7.8} \mathrm{~A}$ cárie dentária pode servir como porta de entrada para infecções em imunocomprometidos e o aumento de sua incidência está relacionada com a pobre higiene oral, alteração do $\mathrm{pH}$ da saliva e dieta. ${ }^{7}$ 
A incidência de cárie dentária em indivíduos com falência renal crônica é baixa, sendo 30\% menor em crianças, se comparada com um grupo de crianças normais. ${ }^{5}$ Entretanto, o risco de cárie aumenta após o transplante renal, provavelmente por haver aumento na contagem de Streptococos mutans ${ }^{5}$ e, também, associado à pobre higiene oral. ${ }^{4}$ Nowaiser et al. ${ }^{4}$ encontraram um número significativamente maior de S.mutans em crianças antes do transplante renal e 90 dias depois do transplante, comparado com o grupo-controle. O mesmo não ocorreu para a contagem de Lactobacillus e Candida albicans. ${ }^{4}$

Durante o período anterior ao transplante, alguns indivíduos podem negligenciar a saúde oral, não removendo infecções dentárias, que podem ser precursoras potenciais para doenças dentárias ${ }^{6} \mathrm{e}$ manifestações sistêmicas relacionadas a esses focos infecciosos. A utilização de medicamentos diuréticos, a rádio e a quimioterapia ocasionam redução do fluxo salivar, o que pode gerar aumento da incidência de cárie dentária. ${ }^{6}$

\section{Doenças pulpares}

As infecções bucais de origem odontogênica surgem mais comumente na polpa e nas regiões periapicais. $\mathrm{O}$ principal agente causador dessas infecções são as bactérias, e elas ocorrem devido à exposição da polpa (feixe vásculo-nervoso que dá vitalidade ao dente) pela cárie dentária, permitindo infecção maciça do interior do elemento dental pelas bactérias da boca. Em condições adequadas, os microorganismos multiplicam-se e superam as defesas do hospedeiro no local. ${ }^{9}$

A resposta da polpa às infecções microbianas pode ser proliferativa, inflamatória e por alterações degenerativas. Essas condições permitem que ocorram vasodilatação no ápice dentário, reabsorção óssea, aumento de células gigantes e, dependendo da virulência dos microorganismos e da resistência do hospedeiro, a formação de exsudato purulento. ${ }^{9}$

Rocha et al isolaram 137 cepas bacterianas de 30 lesões de periápice. Do total de bactérias isoladas, $90(65,7 \%)$ foram caracterizadas como anaeróbias estritas, 40 (29,2\%), anaeróbias facultativas e sete $(5,1 \%)$ aeróbias estritas. ${ }^{10}$ Os microorganismos mais freqüentes podem ser encontrados na tabela 1.

Um dos principais aspectos relacionados ao êxito dos transplantes é a prevenção de infecções, pois, devido à imunossupressão, qualquer microorganismo é capaz de originar um processo que pode colocar em risco a vida do paciente. ${ }^{11,12}$ As infecções de origem odontogênica podem progredir por extensão direta, por via sanguínea ou linfática para outras áreas distantes do foco primário da infecção. ${ }^{9}$ Apesar de a literatura não apresentar vasta documentação mostrando que infecções de origem odontogênica têm impacto significante em candidatos a transplante ou em receptores de transplantes de órgãos, trabalhos têm sido publicados recomendando a remoção de focos infecciosos bucais previamente aos transplantes. ${ }^{12}$ Reyna et al (1982) encontraram três casos de abscessos dentais em pacientes transplantados renais. ${ }^{3}$ Avaliando 80 pacientes pré-transplante hepático, outros autores observaram que $20 \%$ destes apresentavam infecções periapicais. ${ }^{13}$

O tratamento das infecções e dos abscessos de origem dental segue os critérios clínicos e cirúrgicos de remoção do foco infeccioso associado ao uso racional dos antibióticos ${ }^{9}$ e devem ser removidos preferencialmente antes dos transplantes. A bacteremia provocada
Tabela 1. Espécies bacterianas isoladas de lesões periapicais (Rocha et al, 1996)

\begin{tabular}{|c|c|}
\hline BACTÉRIAS & QUANTIDADE (n) \\
\hline \multicolumn{2}{|l|}{ Cocos Gram-positivos } \\
\hline Streptococcus sanguis II & 7 \\
\hline S. do grupo viridans & 4 \\
\hline S. mitis & 14 \\
\hline S. acidominimus & 1 \\
\hline S. do grupo mutans & 2 \\
\hline S. milleri & 4 \\
\hline S. intermedius & 1 \\
\hline Staphylococcus epidermidis & 3 \\
\hline S. xylosus & 2 \\
\hline S. warneri & 2 \\
\hline Peptostreptococcus sp & 15 \\
\hline \multicolumn{2}{|l|}{ Cocos Gram-negativos } \\
\hline Veillonella sp & 6 \\
\hline \multicolumn{2}{|l|}{ Bacilos Gram-positivos } \\
\hline Corynebacterium xerosis & 1 \\
\hline Corynebacterium sp & 5 \\
\hline Bacilos Gram (+) não esporulados & 11 \\
\hline \multicolumn{2}{|l|}{ Bacilos Gram-negativos } \\
\hline Xantomonas maltophilia & 1 \\
\hline Fusobacterium nucleatum & 28 \\
\hline Bacilos Gram(-) pigmentados & 24 \\
\hline Bacteroides sp & 6 \\
\hline
\end{tabular}

por manipulação odontológica, quando o paciente está imunossuprimido, representa um significante potencial de risco infeccioso para disseminação sistêmica. ${ }^{12,14}$

\section{Doenças periodontais}

As doenças periodontais ocorrem quando esses tecidos (gengiva, osso, ligamento periodontal e cemento) estão em condições patológicas, e genericamente podem ser divididas em duas entidades principais: gengivite e periodontite. ${ }^{15}$

A gengivite geralmente está restrita à gengiva marginal e caracteriza-se pela formação de processo inflamatório, gerando sangramento ao toque ou espontâneo, às vezes acompanhado de mudança de coloração e de volume. As causas são, principalmente, agressão por toxinas eliminadas pelo biofilme dental, mas também podem ser manifestações bucais secundárias a alterações sistêmicas. Não está associada à destruição dos tecidos de suporte periodontal, como ligamentos e osso alveolar. ${ }^{16}$

A periodontite é uma alteração patológica destrutiva e progressiva que leva à perda de inserção óssea do elemento dental, através da contaminação do cemento dentário e da destruição dos ligamentos periodontais e do osso alveolar, formando a bolsa periodontal. ${ }^{17}$ A periodontite pode evoluir para abscessos, causando intensa secreção purulenta, dor e tumefação. ${ }^{18}$ 
Baseado em métodos tradicionais e nas últimas tecnologias de biologia molecular do estudo de culturas bacterianas, foram identificadas mais de 700 espécies de bactérias na cavidade oral, sendo que mais de 400 dessas espécies colonizam a região da bolsa periodontal e cerca de 300 colonizam outras regiões como dorso de língua, cáries e mucosa oral. ${ }^{19}$ Geralmente, um indivíduo apresenta em sua flora bucal de 100 a 200 espécies das identificadas, mas a variedade de individuo para individuo é bastante grande. Em relação às doenças periodontais, Socransky et al (1998) sugerem que grupos de bactérias podem ser encontrados atuando juntos no desenvolvimento e na manutenção dessas patologias em cada individuo. ${ }^{20}$ Em transplantados e candidatos a transplante, a literatura relata a influência desses focos bucais e seus patogenos na liberação de Proteína $\mathrm{C}$ reativa, bacteremias, sepses, endocardites e outras doenças cardiovasculares..$^{21-24}$

Em alguns casos, como nos candidatos a transplantes renais, o índice de doença periodontal é elevado, pois a xerostomia causada pela falência renal, a diálise e os efeitos colaterais das medicações contribuem para o agravamento da doença periodontal, e aproximadamente $50 \%$ dos candidatos a transplante têm 50 anos ou mais, idade de maior prevalência dessa patologia. ${ }^{12}$

Outra importante manifestação bucal no periodonto é o crescimento gengival induzido pelo uso de inibidores da Calcineurina, especialmente a Ciclosporina A. ${ }^{25,26}$ No paciente susceptível, o crescimento gengival pode se iniciar no primeiro semestre após o transplante, atingindo extensões variáveis, desde pequenas alterações em papilas gengivais até a cobertura total da coroa dental. Consequentemente podem ocorrer interferências na oclusão dos dentes, mastigação e fala, o que induz a deficiências nutricionais e, em crianças, alteração da cronologia de erupção dos dentes. ${ }^{27}$ $\mathrm{O}$ crescimento gengival dificulta a higienização nas regiões bucais acometidas, tendo como resultado problemas infecciosos, hemorrágicos e estéticos para o paciente, formando focos que poderão gerar bacteremia e sepse..$^{16,28,29}$

O aumento gengival propicia o acúmulo do biofilme bacterianol sobre a superfície dental, gerando fenômenos inflamatórios gengivais, o que exige avaliação e controle profissional mais apurado na prevenção de episódios infecciosos desses pacientes ${ }^{26}$. A prevenção com higiene oral adequada é importante no controle do componente inflamatório e diminui a gravidade da HGM. Embora haja grande risco de recidivas nos tratamentos propostos para HGM, estes podem ser realizados através de remoção cirúrgica do excesso gengival ou tratamento alternativo, com utilização de antibióticos (especialmente a azitromicina), ou laserterapia, citada em estudos recentes. ${ }^{30}$ A substituição da Ciclosporina pelo tacrolimo também foi sugerida como tratamento para HGM, mas as lesões podem persistir após a troca do imunossupressor. ${ }^{26}$

\section{Infecções oportunistas pós-transplante}

Estudos avaliando a prevalência de lesões estomatológicas em pacientes transplantados de órgãos sólidos são pouco comuns na literatura, dificultando a compreensão da influência que os processos infecciosos orais podem exercer na integridade sistêmica desses pacientes. Segundo Carvalho et al, a imunossupressão prolongada influencia os mecanismos de defesa dos pacientes transplantados, podendo haver aumento da susceptibilidade a diversas infecções oportunistas, sejam elas de origem viral, fúngica ou bacteriana. ${ }^{31}$
Silva \& Figueiredo avaliaram a presença de lesões orais em um grupo de 32 transplantados renais e observaram que aproximadamente $72 \%$ destes exibiram alguma alteração estomatológica. Herpes simples e Candidose foram as lesões mais comuns, aparecendo em respectivamente $46,8 \%$ e $40,6 \%$ dos casos (Figuras 1 e 2 ). Papilomas, leucoplasia pilosa, hiperplasia gengival, tuberculose e aspergilose também foram verificadas em menor frequência. ${ }^{32}$

Infecções por Herpes vírus são causas comuns de morbidade e mortalidade em pacientes transplantados de órgãos sólidos e de medula óssea. Mecanismos de adaptação persistentes são características desses tipos de vírus. O equilíbrio entre a persistência viral e regulação imunológica do hospedeiro é mantida em indivíduos saudáveis, mas pode ser alterada em muitas condições imunológicas associadas ao transplante de órgãos. ${ }^{33} \mathrm{Na}$ cavidade oral, os herpes vírus humanos representam um grupo amplo de vírus DNA que se associam a diversas doenças de boca. Nessa família de vírus, incluem-se o herpes simples (HSV ou HHV-1 e 2), o vírus da varicela-zoster (VZV ou HHV-3), vírus

Figura 1. Candidose Pseudo-membranosa em palato duro

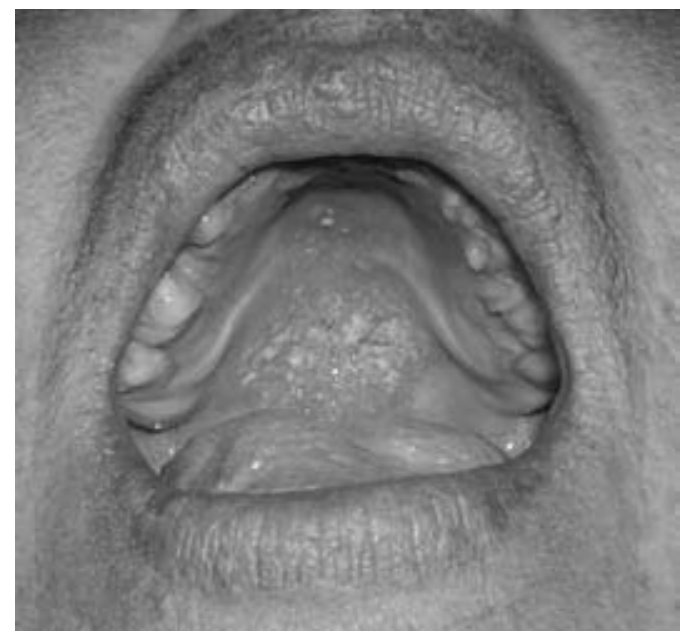

Figura 2. Herpes simples lingual e em comissura labial

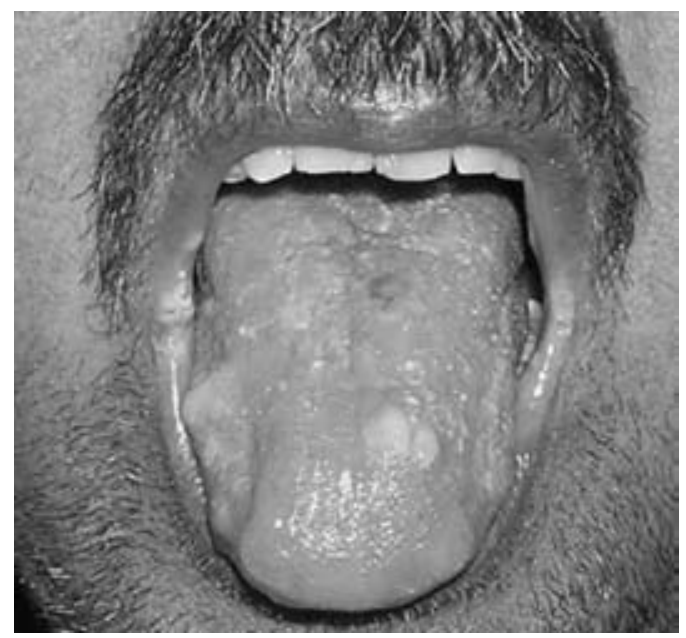


Epstein-Barr (EBV ou HHV-4), citomegalovirus (CMV ou HHV-5), dentre outros descobertos recentemente (HHV-6, 7 e 8). Infecções disseminadas da mucosa oral pelo HSV, incluindo mucosa nãoqueratinizada e ulcerações bucais pelo CMV são descritas em pacientes imunodeprimidos. ${ }^{29,34}$

Em estudo realizado por Guleç et al, 102 pacientes transplantados foram investigados quanto à presença de infecções fúngicas superficiais relacionadas à terapia imunossupressora, e observaram que $63,7 \%$ dos pacientes avaliados apresentaram-se comprometidos, sendo a Pitiríase vesicolor e Candidose oral as lesões mais comuns. ${ }^{35}$ Nas lesões orais, a Candida albicans foi o agente mais identificado, e fatores como idade, sexo e tempo de terapia imunossupressora não foram significantes. ${ }^{34}$ Entretanto, outras espécies menos comuns são observadas, como Candida tropicalis, Candida glabrata e Candida krusei e também podem causar infecções, principalmente em pacientes imunossuprimidos e neutropênicos Pacientes transplantados são incluídos por aqueles autores no grupo de pacientes associados a fatores sistêmicos de risco para desenvolvimento de Candidose oral.

\section{Alterações dentárias e maxilares}

Alterações significativas no desenvolvimento de dentes e estruturas ósseas maxilares estão associadas a diversos fatores como altos níveis de uréia, agentes antineoplásicos e o uso de imunossupressores. ${ }^{36,37}$

Na maioria de pacientes pediátricos e adolescentes submetidos a altas doses de quimioterápico para Transplante de Medula Óssea foram identificadas alterações no desenvolvimento radicular. ${ }^{38}$ Sonis et al (1990) constataram que anormalidades no desenvolvimento dental ocorreram em 94\% dos pacientes, em $100 \%$ dos pacientes com idade inferior a cinco anos e naqueles que receberam radioterapia. Anormalidades craniofaciais fizeram-se presentes em 90\% dos pacientes com idade inferior a cinco anos que receberam quimioterapia mais radioterapia, com significativa deficiência do desenvolvimento mandibular. ${ }^{39}$ A gravidade das anomalias de desenvolvimento dentofacial secundárias ao TMO relaciona-se com a idade do paciente ao início do tratamento quimioterápico e ao uso da radiação ionizante..$^{39,40}$

O acompanhamento clínico e radiográfico de pacientes com alterações dentofaciais é fundamental na prevenção de quadros infecciosos agudos apicais, assim como são relevantes para a correção dos defeitos maxilofaciais através de correções ortopédicas funcionais e/ou ortodônticas. ${ }^{41,42}$ Análise da condição sistêmica associada à possibilidade de manter um controle efetivo da correção ortodôntica será determinante na continuidade ou não desse tratamento em portadores de alterações sistêmicas e transplantes de órgãos e tecidos. ${ }^{43}$

\section{Alterações bucais em transplantados de medula óssea}

A tendência ao sangramento devido trombocitopenia por supressão da medula óssea em pacientes submetidos a TMO, ${ }^{44,45}$ é aumentada pela higiene oral deficiente e acúmulo de placa bacteriana que, juntamente com fatores locais, acentuam a resposta inflamatória dos tecidos periodontais. ${ }^{46}$ Alterações orais como petéquias e sangramentos gengivais são freqüentemente encontrados. ${ }^{47}$
A mucosite oral é uma sequela do tratamento citoredutivo induzido por radioterapia e/ou quimioterapia, sendo a causa mais comum de dor oral durante o tratamento antineoplásico e a complicação mais comum em pacientes submetidos a transplante de medula óssea. ${ }^{48,49}$

Os sinais e os sintomas iniciais da mucosite oral incluem eritema, edema, sensação de ardência e sensibilidade aumentada a alimentos quentes ou ácidos. ${ }^{50}$ Cursa com ulcerações dolorosas recobertas por exsudato fibrinoso (pseudomembrana) ${ }^{51}$ de coloração esbranquiçada ou opalescente. Essas úlceras podem ser múltiplas e extensas, levando à má nutrição e à desidratação. ${ }^{52}$ Além da importante sintomatologia, as ulcerações aumentam o risco de infecção local e sistêmica, comprometem a função oral e interferem no tratamento antineoplásico, podendo levar à sua interrupção, o que compromete a sobrevida do paciente..$^{52,53}$

Efeitos da quimioterapia em glândulas salivares menores são bem documentados. ${ }^{54,55} \mathrm{Um}$ estudo piloto de pacientes com doenças hematológicas malignas e que receberam quimioterapia demonstraram redução da secreção das glândulas salivares menores em comparação com secreção das glândulas salivares principais. ${ }^{55}$ O comprometimento funcional da glândula salivar maior pode ser difícil de avaliar clinicamente, o que vem a ser uma questão crítica em pacientes transplantados e pode ter influência na qualidade de vida, infecções e outras complicações. ${ }^{56}$

Em pacientes submetidos a transplante alogênico ou singênico de medula óssea, a ocorrência de doença do enxerto contra o hospedeiro (GVHD) é comum, envolvendo aproximadamente $20 \%$ a $80 \%$ dos pacientes e, na forma crônica, a sobrevida em cinco anos está em torno de $40 \% .^{57,58} \mathrm{O}$ envolvimento das glândulas salivares é comum, podendo ser visto no período precoce do transplante de medula óssea ${ }^{56}$, bem como tardiamente com o desenvolvimento do GVHD. ${ }^{59}$ Nota-se redução entre 55\%-90\% no fluxo salivar em pacientes com GVHD, revelando que essa redução pode acontecer em $39 \%$ e $70 \%$ nos 2 e 12 meses, respectivamente. ${ }^{60}$ Portanto, as glândulas salivares são sensíveis como métodos de diagnóstico para o GVHD oral. ${ }^{61}$ Sendo o GVHD a condição de maior morbidade em longo prazo em pacientes submetidos a transplante alogênico de medula óssea, Santos et al. (2005) sugerem a avaliação bucal e o tratamento de todas as fontes de infecção bucal em potencial devem se tornar padrão de cuidados para estes pacientes. ${ }^{62}$

\section{Impacto econômico da atuação do cirurgião dentista diante das complicações bucais nos pacientes transplantados}

As infecções de origem bucal podem influenciar no sucesso dos transplantes, se não diagnosticadas e tratadas previamente aos procedimentos que induzirão os pacientes ao estado de imunossupressão. Rustemyer e Bremerich avaliaram 70\% dos indivíduos de uma amostra de 204 pacientes em programação de transplantes de órgãos sólidos que necessitaram de procedimentos cirúrgicos odontológicos para remoção de agentes infecciosos antes de transplantes de coração, fígado e válvula cardíaca, enquanto $84 \%$ foram necessários antes de transplante renal. ${ }^{63}$

Sonis et al (2001) destacaram os custos relacionados a pacientes que desenvolveram mucosite oral grave, os quais aumentaram em cerca de U\$43.000 os custos hospitalares quando comparados com os pacientes que não apresentaram mucosite oral grave. ${ }^{64}$ 
A atuação do cirurgião dentista no combate a complicações orais como a mucosite em transplantados de medula óssea representa uma interferência benéfica, promovendo tentativas de redução significativa no tempo de internação, diminuição da quantidade de medicação (analgésicos), promovendo melhorias nutricionais e redução no consumo de materiais descartáveis (seringas, catéteres e sondas nasogástricas). ${ }^{65}$

\section{CONCLUSÃO}

A cavidade oral é sitio de grande diversidade de agentes microbianos e o risco de infecção e sepsis a partir de um foco dentário e/ou periodontal, bem como do surgimento de lesões infecciosas oportunistas antes ou depois de transplante pode ser relevante e interferir no sucesso terapêutico dos pacientes. O diagnóstico precoce dessas alterações está associado ao melhor prognóstico de pacientes transplantados. Avaliações odontológicas pré e pós-transplantes devem ser rotineiras nos centros, para evitar que alterações bucais possam trazer comprometimento maior à qualidade de vida dos receptores de órgãos e tecidos. De forma ideal, então, a inclusão de profissionais da Odontologia nas equipes interdisciplinares de transplantes de órgãos sólidos e tecidos contribui para o melhor seguimento destes pacientes.

\section{ABSTRACT}

Oral complications may be important for investigate systemic complications especially related to the immunosuppression condition in transplants and with risk of infections. With the increasing amount of organ and tissue transplanted patients, it has become essential to have multidisciplinary teams to take care of transplanted patients, and among them, dentistry can and should be a part. This literature review intends to present and discuss the relevance of oral complications related to organ and tissue transplants before and after the transplant that can lead to severe complications interfering in a successful medical therapy.

Keywords: Oral Manifestations, Dentistry, Transplantation, Bone marrow transplantation, Bacterial infections, Virus diseases, Mycoses.

\section{REFERÊNCIAS}

1. Featherstone J. Dental caries: a dynamic disease process. Aust Dent J. 2008;53:286-91.

2. Wilson RL, Martinez-Tirado J, Whelchel J, LordonRE. Occult dental infection in renal transplant patients. Am J Kidney Dis. 1982;2:354-6.

3. Reyna J, Richardson JM, Mattox DE, Banowsky LH, Nicastro-Lutton JJ. Head and neck infection after renal transplantation. JAMA. 1982;247:3337-9.

4. Al Nowaiser A, Lucas VS, Wilson M, Roberts GJ, Trompeter RS. Oral health and caries related microflora in children during the first three months following renal transplantation. Int J Paediatr Dent. 2004;14:118-26.

5. Lucas VS, Roberts GJ. Oro-dental health in children with chronic renal failure and after renal transplantation: a clinical review. Pediatr Nephrol. 2005;20:1388-94. Epub 2005 Jun 10. Review.

6. Guggenheimer J, Eghtesad B, Close JM, Shay C, Fung JJ. Dental health status of liver transplant candidates. Liver Transpl. 2007,13:280-6.

7. Vaughan MD, Rowland CC, Tong X, Srivastava DK, Hale GA, Rochester R, et al Dental abnormalities in children preparing for pediatric bone marrow transplantation. Bone Marrow Transplant. 2005;36:863-6.

8. Vaughan MD, Rowland CC, Tong X, Srivastava DK, Hale GA, Rochester R et al. Dental abnormalities after pediatric bone marrow transplantation. Bone Marrow Transplant. 2005;36:725-9

9. Topazian RG, Goldberg MH, Hupp J.R. Infecções orais e maxilofaciais. Ed. 4a 2006; caps. 2 e 7 .

10. Rocha MMNP; Moreira JLB; Menezes DB; Cunha MPSS; Carvalho CBM. Estudo bacteriológico de lesões periapicais. Rev Odontol Univ São Paulo. 1998;12:215-23.

11. López B, García A, Prieto M, Berenguer J. Monitorización del injerto y del paciente. Inmunosupresión de mantenimiento. Profilaxis antibiótica. En: Berenguer J, Parrilla P, eds. Trasplante hepático. Madrid: Elba Editores; 1999. p.331-40.

12. Guggenheimer J, Eghtesad B, Stock DJ. Dental management of (solid) organ transplant patient. Oral Surg Oral Med Oral Pathol. 2003;95:383-9.

13. Barbero P, Garzino Demo MG, Milaneso M, Ottobrelli A. The dental assessment of the patient waiting for a liver transplant. Minerva Stomatol. 1996;45:431-9.
14. Ortiz MLD, Llorens JMM, Albiol JG, Comellas CB, Aytes LB, Escoda CG. Estudio del estado bucodental del paciente trasplantado hepático. Med Oral Patol Oral Cir Bucal. 2005;10:66-76.

15. Armitage GC. Development of a classification system for periodontal diseases and conditions. Ann Periodontol. 1999;4(1):1-6.

16. Brunetti MC, Fernandes M, Moraes RGM. Fundamentos da Periodontia Clínica. $1^{\mathrm{a}}$ ed. São Paulo: Artes Médicas; 2007, 353.

17. Cortelli JR, Lotufo RFM, Oppermann RV, Sallum AW. [Organizadores]; Vários autores. Glossário da Sociedade Brasileira de Periodontologia, São Paulo: SOBRAPE, vol.15, n.04,2005,56.

18. Lindhe J, Karring T, Lang NP. Tratado de Periodontia Clínica e Implantologia Oral. $4^{\mathrm{a}}$ ed. Rio de Janeiro: Guanabara Koogan;2005,1013.

19. Paster BJ, Olsen I, Aas JA, Dewhirst FE. The breadth of bacterial diversity in the human periodontal pocket and other oral sites. Periodontology2000. 2006;42:80-7.

20. Socransky SS, Haffajee AD, Cugini MA, Smith C, Kent RL JR. Microbial complexes in subgingival plaque. J Clin Periodontol. 1998;25:134-44.

21. D'Aiuto F, Ready D, Tonetti MS. Periodontal disease and C-reactive proteinassociated cardiovascular risk. J Periodont Res. 2004;39:236-41.

22. Defraigne JO, Demoulin JC, Piérard GE, Detry O, Limet R. Fatal mural endocarditis and cutaneous botryomycosis after heart transplantation. Am J Dermatopathol. 1997;19:602-5.

23. Kasper EK. Management of potential cardiac recipients awaiting transplantation. In: Baumgartner WA, Reitz B, Kasper E, Theodore J, editors. Heart and lung transplantation. Philadelphia: WB Saunders Co; 2002, p. 90-98.

24. Genctoy G, Ozbek M, Avcu N, Kahraman S, Kirkpantur A, Yilmaz R et al. Gingival health status in renal transplant recipients: relationship between systemic inflammation and atherosclerosis. Int J Clin Pract. 2007;61:577-82.

25. Rateitschak-Plüss EM, Hefti A, Lörtscher R, Thiel G. Initial observation that cyclosporin-A induces gingival enlargement in man. J. Clin Periodontol. 1983;10:237-46.

26. Ellis JS, Seymour RA, Taylor JJ, Thomason JM. Prevalence of gingival overgrowth in transplant patients immunossuppressed with tacrolimus. J Clin Periodontol. 2004;31:126-31. 
27. Kilpatrick NM, Weintraub RG, Lucas JO, Shipp A, Byrt T, Wilkinson JL. Gingival overgrowth in pediatric heart and heart-lung transplant recipients. J Heart Lung Transplant. 1997;16(12):1231-7.

28. Seymour R A, Smith DG, Rogers SR. The comparative effects of azathioprine and cyclosporin on some gingival health parameters of renal transplant patients. A longitudinal study. J Clin Periodont. 1987;4:610-3.

29. Lima RB, Santos PSS, Malafronte P, Muller H, Caiaffa-Filho HH, Sens YAS. Oral manifestation of Cytomegalovirus associated with Herpes Simplex Virus in renal transplant recipient. Transp Proceed. 2008;40:1378-81.

30. Hood KA. Drug-induced gingival hyperplasia in transplant recipients. Prog Transplant. 2002;12(1):17-21.

31. Carvalho AAT, Figueira MAS, Melo SHL. Transplante renal: influencia da terapia imunossupressora na prevalência de manifestações estomatológicas. Odontol Clin Cientif. 2003;2:165-74

32. Silva AAS, Figueiredo MAS. Manifestações estomatológicas em pacientes receptores de transplante renal sob terapia imunossupressora: avaliação clínica de 1 ano. Rev Odonto Ciência. 1998;25:49-75.

33. Razonable RP, Paya CV. B-herpesviruses in transplantation. Rev Med Microbiol 2002;13:163-9.

34. Silverman S, Eversole LR, Truelove EL. Fundamentos de Medicina Interna. Ed Guanabara Koogan. Rio de Janeiro. 2004;cap 4.

35. Gulleç AT, Demirbilek M, Seçkin D, Can F, Saray Y, Sarifakiogluu E, et al.. Superficial fungal infections in 102 patients renal transplant recipients: a case-control study. J Am Acad Dermatol. 2003;49:187-92.

36. Summers SA, Tilakaratne WM, Fortune F, Ashman N. Renal disease and the mouth Am J Med. 2007;120(7):568-73.

37. Lucas VS, Roberts GJ. Oro-dental health in children with chronic renal failure and after renal transplantation: a clinical review. Pediatr Nephrol 2005;20(10):1388-94

38. Rosenberg SW, Kolodney H, Wong GY, Murphy ML. Altered dental root development in long-term survivors of pediatric acute lymphoblastic leukemia. A review of 17 cases. Cancer. 1987;59(9):1640-8.

39. Sonis AL, Tarbell N, Valachovic RW, Gelber R, Schwenn M, Sallan S. Dentofacial development in long-term survivors of acute lymphoblastic leukemia. A comparison of three treatment modalities. Cancer 1990;66(12):2645-52.

40. Zarina RS, Nik-Hussein. Dental abnormalities of a long-term survivor of a childhood hematological malignancy: literature review and report of a case. J Clin Pediatr Dent. 2005; 29(2):167-74.

41. da Fonseca MA. Long-term oral and craniofacial complications following pediatric bone marrow transplantation. Pediatr Dent. 2000;22(1):57-62.

42. Luiz AC, Eduardo FP, Bezinelli LM, Correa L. Alterações bucais e cuidados orais no paciente transplantado de medula óssea. Rev Bras Hematol Hemoter 2008;30(6):480-7.

43. Burden D, Mullally B, Sandler J. Orthodontic treatment of patients with medical disorders. Eur J Orthod. 2001;23:363-72.

44. Keating MJ, Kantarjian H. Leucemias crônicas. In: Goldman L, Ausiello D. Cecil. Tratado de Medicina Interna. 22a ed, Editora Elsevier; 2005.p.1331.

45. Appelbaum FR. Leucemias agudas. In: Goldman L, Ausiello D. Cecil. Tratado de Medicina Interna. 22a ed. Editora Elsevier. 2005. p.1344-50.

46. Sonis ST, Fazio RC, Fang L. Doenças malignas do sangue. In: Sonis ST, Fazio RC Fang L. Princípios e prática de medicina oral. $2^{\mathrm{a}}$ ed. Rio de Janeiro: Guanabara Koogan;1996. p.225-238.
47. Dreizen S, McCredie KB, Bodey GP, Keating MJ. Quantitative analyses of the oral complications of antileukemia chemotherapy. Oral Surg Oral Med Oral Pathol. 1986;62(6):650-3

48. Sonis S, Kunz A. Impact of improved dental services in the frequency of oral complications of cancer therapy for patients with non-head-and-neck malignancies. Oral Surg Oral Med Oral Pathol. 1988;65(1):19-22.

49. Epstein JB, Schubert, MM. Oral mucosistis in myelosuppressive cancer therapy. Oral Surg Oral Med Oral Pathol Radiol Endod. 1999;88(3):273-6.

50. Santos PSS, Magalhães MHCG. Avaliação da mucosite oral em pacientes que receberam adequação bucal prévia ao transplante de medula óssea. RPG Rev Pós Grad. 2006;13:77-82.

51. Meraw SJ, Reeve CM. Dental considerations and treatment of oncology patient receiving radiation therapy. J Am Dent Assoc. 1998;129(2):201-5.

52. Köstler WJ, Hejna M, Wenzel C, Zielinski CC. Oral mucositis complicating chemotherapy and/or radiotherapy: options for prevention and treatment. CA Cancer J Clin. 2001;51(5):290-315.

53. Santos PSS, Guare RO, Fachin LV, Correa MSNP. Transplante de medula óssea: considerações gerais e manifestações bucais em pacientes odontopediátricos. Rev Assoc Paul Cir Dent. 2008;62:450-4.

54. Lockhart PB, Sonis ST. Alterations in the oral mucosa caused by chemotherapeutic agents. A histologic study. J Dermatol Surg Oncol 1981;7:1019-25.

55. Blomgren J, Jansson S, Rodjer S, Birkhed D. Secretion rate from minor salivary glands in patients with malignant haematological diseases receiving chemotherapy - a pilot study. Swed Dent J. 2002;26:75-80.

56. Coracin FL, Pizzigatti Correa ME, Camargo EE, Peterson DE, Oliveira Santos A, Vigorito AC, et al. Major salivary gland damage in allogeneic hematopoietic progenitor cell transplantation assessed by scintigraphic methods. Bone Marrow Transplant. 2006;37:955-9.

57. Akpek G. Titrating graft-versus-host disease: is it worth a try? Bone Marrow Transplant. 2006;38(10):653-6.

58. Schubert MM, Correa ME. Oral graft-versus-host disease. Dent Clin North Am. 2008;52(1):79-109.

59. Alborghetti MR, Corrêa ME, Adam RL, Metze K, Coracin FL, de Souza CA. Late effects of chronic graft-vs.-host disease in minor salivary glands. J Oral Pathol Med. 2005;34(8):486-93

60. Nagler RM, Nagler A. Salivary gland involvement in graft-versus-host disease: the underlying mechanism and implicated treatment. Isr Med Assoc J. 2004;6(3):167-72.

61. Nakhleh RE, Miller W, Snover DC. Significance of mucosal vs salivary gland changes in lip biopsies in the diagnosis of chronic graft-vs-host disease. Arch Pathol Lab Med. 1989;113(8):932-4

62. Santos PSS, Lima RB, Magalhães MHCG. Doença do Enxerto-Contra-Hospedeiro $(\mathrm{DECH})$ em pacientes transplantados de medula óssea - relato de caso. RPG. Revista de Pós-Graduação (USP). 2005;12:506-11.

63. Rustemeyer J, Bremerich A. Necessity of surgical dental foci treatment prior to organ transplantation and heart valve replacement. Clin Oral Invest. 2007;2(11):171-4

64. Sonis ST, Oster G, Fuchs H, Bellm L, Bradford WZ, Edelsberg J et al. Oral mucositis and the clinical and economic outcomes of hematopoietic stem-cell transplantation. J Clin Oncol 2001; 19(8):2201-5.

65. Murphy BA. Clinical and economic consequences of mucositis induced by chemotherapy and/or radiation therapy. J Support Oncol. 2007; 5(9):13-21. 